Respiration 1989;55(Suppl.1):41-43

\title{
Lung Defensive System: Damages and Treatment
}

\section{Pulmonary Surfactant and Respiratory Infections}

Bisetti, A 45

Attachment of Streptococcus pneumoniae to Human Pharyngeal Epithelial Cells

Andersson, B.; Svanborg-Edén, C 49

Relationship between Changes in Alveolar Surfactant Levels and Lung Defence

Mechanisms

Pozzi, E.; Luisetti, M.; Spialtini, L.; Coccia, P.; Rossi, A.; Donnini, M.; Cetta, G.; Salmona. M 53

Role of Surfactant in Alveolar Defence against Inhaled Particles

Curti, P.C.; Genghini, M 60

Antioxidant Defences of Rabbit Alveolar Lining Fluid

Roveri,AA.; Bruni, R.; Baritussio,_A.; Coassin, M.;Benevento, M.; Maiorino, M.; Ursini,F 68

Ambroxol Inhibits Airway Hyperresponsiveness Induced by Ozone in Dogs

Chitano, P.; Di Stefano, A.; Finotto, S.; Zavattini, G.; Maestrelli, P.; Mapp, C; Fabbri, L.M.;

Allegra, L. 74

Lung Permeability in Smokers after Ambroxol Treatment

Mistretta, A.; Crimi, N.; Palermo, F.; Oliveri, R.; Vancheri, C; Vigneri, G.; Gibellino, F 79

Prevention of Chronic Bronchitis Exacerbations with Ambroxol (Mucosolvan Retard).

An Open, Long-Term, Multicenter Study in 5,635 Patients 84

Author Index 97

Subject Index 99

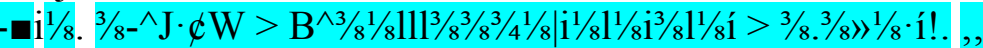

